\title{
The colon mucus antibody
}

\author{
N. M. GIBBS AND L. W. FRENCH \\ From the Department of Histopathology, Central Area Laboratory, St Luke's Hospital, Guildford
}

SYNOPSIS One thousand one hundred and thirty sera from hospital patients under investigation for autoimmune disease were tested for colon mucus antibody and tissue antibodies. The sera with a positive mucus antibody were retested against a panel of test colons of known blood group using IgG, IgA, and IgM antihuman glcbulin fluorescein isothiocyanate conjugate. It was found that there was a variation between the results obtained with different test colons. This was considered to be due to a system in tissues of mucus isoantigens produced by the goblet cells of the colon. Using this panel of test colons raised the percentage of mucus antibodies detected in cases of ulcerative colitis from 14 to $37 \%$. The presence of the mucus antibody was found to be shortlived in some patients. The colon mucus antibody was also found in thyroid disease and chronic asthma and the reasons for this finding are discussed.

Antibodies to colon mucus have been described by various authors (Broberger and Perlman, 1963; Wright and Truelove, 1966) in a small percentage of the blood sera of patients suffering from ulcerative colitis. However, colon mucus antibodies have been described occasionally in patients who did not have intestinal disease and even in normal serum(McGiven, Ghose, and Nairn, 1967; Lagercrantz, Hammarström, Perlmann, and Gustafsson, 1968). The object of this paper is to investigate the colon mucus antibody and tissue antibodies, which were found in the serum of patients under investigation for possible autoimmune disease, with particular reference to chronic ulcerative colitis.

\section{Technical Methods}

Serum from each patient was tested for antibodies to thyroglobulin (tanned red cell agglutination test), gastric parietal cells, colon mucus antibody, rheumatoid factor (latex and sheep cell agglutination test), as well as nuclear, microsomal and mitochondrial antibodies to colon, liver, kidney, adrenal, thyroid, and smooth muscle.

The tanned red cell and sheep cell agglutination tests were carried out as recommended by the WHO international reference centre for immunology.

The tissue and mucus antibody tests were carried out as follows.

Received for publication 8 June 1971.
Test tissues were stored at $-70^{\circ} \mathrm{C}$ and cryostat sections were cut at 4 to $6 \mu$ and dried by fan for 30 minutes at room temperature. A section of each of these tissues was mounted in a predetermined sequence on each slide for testing. Sections which were examined for the mucus antibody were fixed in $100 \%$ ethanol at $20^{\circ} \mathrm{C}$ for five minutes and then rinsed in buffered saline, whereas fresh unfixed tissues were used for the detection of tissue antibodies. The sections were then treated with neat and 1:20 dilution of patient's serum under test for 30 minutes in a damp chamber at $20^{\circ} \mathrm{C}$. They were washed in buffered saline for 30 minutes and incubated in 1:40 dilution of IgG antihuman globulin fluorescein isothiocyanate (FITC) conjugate (Burroughs Wellcome \& Co.). The sections were finally washed for two hours in buffered saline, mounted in glycerol, and examined immediately by fluorescent microscopy.

Patients' sera showing a mucus antibody were retested with IgA and IgM antihuman globulin FITC conjugate (Nordic).

Fifty-two sera showing a positive colon mucus antibody were retested with multiple colon tissues of known blood group. Fifty antenatal control normal sera were also tested against the same colon tissues.

Ten cases with a positive colon mucus antibody were followed up between three and 12 months of the initial test. 


\section{Results}

Tissue antibodies were found in various autoimmune diseases and these were active against similar structures in the various organs tested and in no way specific to colon. Moreover no tissue antibodies to colon were detected in patients suffering from chronic ulcerative colitis, although the rheumatoid factor $(8 \%)$ and thyroglobulin antibody $(2 \%)$ were found occasionally. Mucus antibody was found in patients suffering from chronic ulcerative colitis $(14 \%$, Table I) and also in two other groups of patients, namely, chronic asthma $(38 \%)$ and thyroid disease $(5 \%)$. The colon mucus antibody was not found in a small series of patients suffering from Crohn's disease.

\begin{tabular}{lcc}
\hline Condition & Number Tested & $\begin{array}{l}\text { Positive Mucus } \\
\text { Antibodies }\end{array}$ \\
\hline Ulcerative colitis & 110 & $15(14 \%)$ \\
Thyroid disease & 297 & $15(5 \%)$ \\
Asthma & 139 & $5(3.8 \%)$ \\
Crohn's disease & 11 & 0 \\
Miscellaneous & 573 & $7(1.2 \%)$ \\
Total & 1,130 & $42(4 \%)$
\end{tabular}

Table I Mucus antibody in various conditions

The mucus antibody was low in titre and was present in surface extracellular mucin and intracellular goblet cell mucin of the colon glands. The antibody was detected in neat serum only in all cases with two exceptions where a titre of $1: 20$ and $1: 80$ respectively was found in serum from two cases of ulcerative colitis.

The positive mucus antibody sera were retested with IgA and IgM antihuman globulin sera but only one mucus antibody was still detected and this was found to be in the IgM range.

Comparison of the results obtained (Table II) with different colon test tissues of known blood group show that the test tissues displayed varying antigenicity and that some gave a higher percentage of positive reactions than others. This variation in antigenicity did not appear to be related to blood group substances, as examples were found in both group $\mathrm{A}$ and $\mathrm{O}$ colons. Forty-nine of the 50 control sera gave negative results with six colon tissues but one positive colon mucus antibody was detected by each colon tissue so that six $(2 \%)$ positive reactions were obtained in 300 tests. The titre of this one antibody was weak and only detectable in neat serum.

\section{ULCERATIVE COLITIS}

Fifteen $(14 \%)$ of 110 sera from patients with ulcerative colitis gave positive results with a single colon
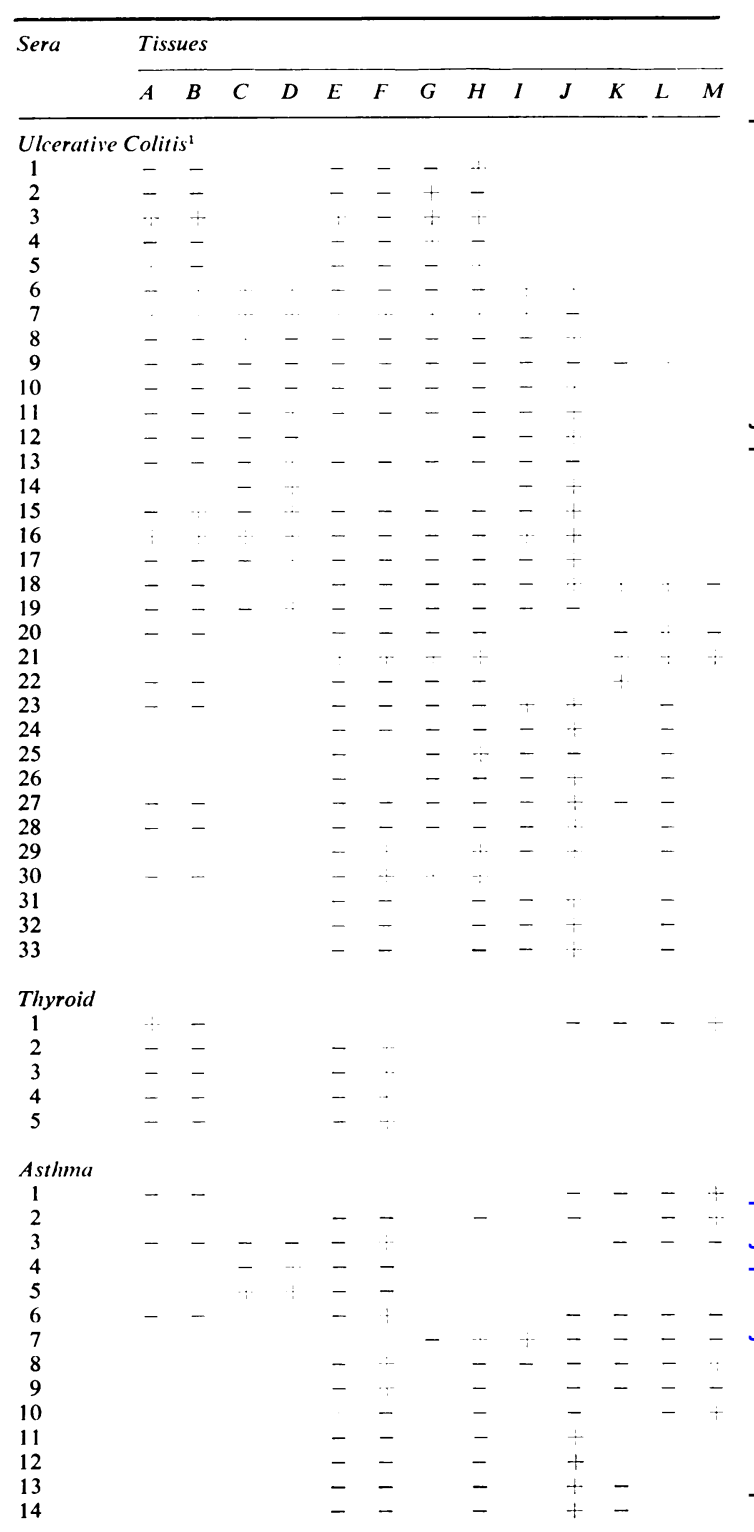

Table II Results in ulcerative colitis, thyroid disease, and asthma

${ }^{1}$ Colon tissues E, F, G, H (blood group A), I (blood group AB), and remainder (blood group $\mathrm{O}$ )

+ positive test, - negative test, blank, no test.

tissue. Eighty-nine of these sera were retested against a panel of colon tissues of known blood group (see Table II). Thus 508 tests were undertaken. Thirtythree $(37 \%)$ sera gave positive reactions with at least one tissue (Table II) and $74(14 \cdot 6 \%)$ positive reactions were given in the 508 individual tests performed. 
Considering the positive cases alone, the 33 sera gave $74(28 \%)$ positive reactions with the 262 colon tissues tested.

\section{ASTHMA}

Fourteen sera which had given a positive reaction with a single colon tissue were retested against multiple colons and $18(21 \%)$ positive reactions were obtained with 84 tests performed (Table II).

\section{THYROID}

Five sera which had given a positive reaction with a single colon tissue were retested against multiple colons and six $(27 \%)$ positive results were obtained on the 22 tests performed (Table II).

\section{ADDITIONAL CASES}

Colon mucus antibodies were encountered in two cases of rheumatoid arthritis and single examples of idiopathic myocarditis, sarcoidosis, haemolytic anaemia, and obstructive jaundice.

Ten cases with positive mucus antibodies had repeat tests within three to 12 months of the initial test using the same test colon. Six of the 10 cases retained the mucus antibody but four became negative.

\section{Discussion}

Colon mucus antibodies were found in ulcerative colitis, chronic asthma, and thyroid disease and also in occasional patients suffering from diseases with a probable autoimmune background. The mucus antibody, with one exception, was low in titre and only detected in neat serum and it was not found in conjunction with tissue antibodies. The fact that the titres were low produced inherent problems in carrying out the tests and the storage of test tissues and sera. The results show that the sera of the patients described contained antibodies to colonic mucus which were not always detectable with single test colon tissues. The reactivity of the colon test tissues with different sera varied considerably, but this reactivity was not dependent on blood group antigens. There was fluorescence of both surface and intracellular mucin in the colon test tissues so it was unlikely that the reaction was influenced by absorption of food or bacterial antigens into the mucus. It would seem that the reactivity of the colon mucus was dependent upon variations based on the chemical composition of the mucus in the test colons. The number of mucus antibodies detected by individual test colons ranged between $8 \%$ and $70 \%$, and it may be that a system in tissue of mucus antigens of varying specificity is involved, which would account for the variations in reactivity between the test colons. Test colons which give a high percentage of positive mucus antibodies have been encountered by at least one observer (Wright and Truelove, 1966). Zweibaum and Steudler (1969) studied natural isoantibodies specific for group antigens in tissue of the colons in the dog and rabbit and found that anticolon isoantibodies are naturally present in normal animals. However, within the limits of the methods used our investigations show that isoantibodies to colon mucus occur naturally in only a small percentage of normal people. It seems reasonable to explain the production of mucus antibodies in chronic asthmatics by a process similar to that which is presumed in ulcerative colitis, namely, by interstitial extravasation of mucus and the activation of local immune mechanisms. Furthermore extravasations of polysaccharide substances occur in thyroid disease and it is possible that these substances have the same antigenic determinants as colon and respiratory mucus.

The use of multiple colon test tissues raised the percentage of positive reactions from 14 to approximately $37 \%$ in 'our experiments which is still a long way short of providing a clinical diagnostic test. However, it seems that the finding of a colon mucus antibody is against the diagnosis of Crohn's disease.

In common with other observers there was no evidence that the presence of the antibody had causative or prognostic significance in colitis, and indeed in the few cases which we followed up the antibody had a limited survival in the sera of some patients.

This research was financed by a research grant from the S.W. Metropolitan Regional Hospital Board.

\section{References}

Broberger, O., and Perlmann, P. (1963). In vitro studies of ulcerative colitis. I. Reactions of patients' serum with human colon fetal cells in tissue cultures. J. exp. Med., 117, 705-716.

Lagercrantz, R., Hammarström, S., Perlmann, P., and Gustafsson. B. E. (1968). Immunological studies in ulcerative colitis. IV. Origin of auto-antibodies. J. exp. Med., 128, 1339-1352.

McGiven, A. R., Ghose, T., and Nairn, R. C. (1967). Auto-antibodies in ulcerative colitis. Brit. med. J., 2, 19-23.

Wright, R., and Truelove, S. C. (1966). Auto-immune reactions in ulcerative colitis. Gut, 7, 32-40.

Zweibaum, A., and Steudler, V. (1969). Natural iso-antibodies specific for tissular group antigens of the colon in dog and rabbit. Nature (Lond.), 223 84-86. 